\title{
Study on Numerical Simulation and Bolt Grouting Mechanism of Mine Fracture rock masses
}

\author{
Yanli LIU ${ }^{1, a}$, Zhiqiang KANG ${ }^{2, b}$, Qingshan $\mathrm{Li}^{3, \mathrm{c}}$, Shuqiang $\mathrm{CHEN}^{4, \mathrm{~d}}$ \\ ${ }^{1}$ Ministry of the basic teaching, Tangshan College, Tangshan 063000, China \\ ${ }^{2}$ College of Mining Engineering, Hebei United University; HeBei Province Key Laboratory of Mining \\ Development and Safety Technique, Tangshan, 063009 China \\ ${ }^{3}$ Hebei Iron and Steel Group Laiyuan Zinc and Molybdenum Mining Co., Ltd., Baoding, 074300 \\ China \\ ${ }^{4}$ Sinosteel Engineering Design and Research Institute, Shijiazhuang and Design Institute, \\ Shijiazhuang, 050021 China \\ a lyl7937@126.com, ${ }^{\mathrm{b}}$ kangzhiqiang@heuu.edu.cn, ${ }^{\mathrm{c}}$ Iqsandssq@163.com, ${ }^{\mathrm{d}}$ 35666455@qq.com
}

Keywords: Optimal anchoring angle; Joints weak face; Shear strength; Numerical simulation.

\begin{abstract}
The constitutive relation such as shear strength and optimal anchoring angle of jointed rock masses are obtained by analyzing the bolt grouting mechanism of mine fracture rock masses. The rock roadway of double-track roadway is simulated respectively by Flac3D software under the condition of no-support and bolting and grouting. The simulation results show that the support with bolting and grouting enhances the bearing capacity of jointed roadway, improves the stress station, and limits the deformation of the jointed roadway rock.
\end{abstract}

\section{Introduction}

Along with fast development of national economy, the development and utilization of underground engineering is increasing aggravate, such as mine, transportation, water conservancy, national defense and so on. These underground engineering are mostly in underground formation. However, discontinuity, anisotropic characteristics were forced to present due to the unceasing movement of crustal rock, mainly in the form of joint, fault, fold, and crack. These discontinuous surfaces reduce the deformation modulus and strength parameters of rock mass, and making rock mass present the obvious anisotropic properties ${ }^{[1,2]}$. Under construction load, vast joints in rock mass start produce, extend and coalescence, leading to deterioration of rock mechanical properties, eventually destroy ${ }^{[3]}$. For example, underground engineering excavation destroys the original balance state of rock mass, making the surrounding rock stress redistribution, causing the deformation, damage, and collapse of surrounding rock. Bolt as the main reinforcement measures are adopted vastly. It has obvious reinforcing effect of jointed rock mass, is a kind of original rocks, safety and reliability, small disturbance of economic effective reinforcement technology, not only improves the rock mass integrity, and conducive to play rock own bearing capacity ${ }^{[4,5]}$.This paper take a underground metal mine roadway as model, using numerical simulation software conducted numerical simulation analysis in jointed rock masses double roadway with bolt supporting, revealing the bolt-grouting to improve the joint soft rock roadway surrounding rock stress condition, and it has the obvious effect to limit the distortion of surrounding rock.

\section{The basic principle of bolt reinforcement in jointed rock mass}

The shear strength of bolted joint includes two aspects; the first is the joint shear strength of weak plane itself. Second is the increase of the shear strength of weak because of the anchor in the joint surface. Thus anchored joint shear strength formula is: $\tau_{j}=\tau_{c}+\tau_{b}$ 
Note: ${ }^{\tau_{j}}$ is the shear strength of bolted joint; $\tau_{c}$ is the shear strength of joints of weak plane; ${ }^{\tau_{b}}$ is the increase of the shear strength by bolt. Among: $\tau_{c}=c_{c}+\sigma_{j} \tan \phi, \tau_{b}=\frac{p_{t s}}{A}$

Note: ${ }^{C_{c}}$ is bonding strength of joint weak surface; ${ }^{\sigma_{j}}$ is normal stress of joint weak surface; $p_{t s}$ is comprehensive shear of bolt in jointed weak surface; $A$ joint area with grappling of rock bolt; $\phi_{\text {is }}$ joint friction angle.

Analyzing from the theoretical, our final purpose is maximize the shear strength of the joint surface. From analyze, we can see that $\frac{\partial p_{s}}{\partial a}=0$

Among $p_{t s}=\sigma s[\cos (\alpha-\beta)+\sin (\alpha-\beta) \tan \phi]+\tau s[\sin (\alpha-\beta)-\cos (a-\beta) \tan \phi]$

Note $\sigma, \tau, \alpha, \beta, S 、 \phi$ are with same parameters with the upper section.

$a=\arctan \left(\frac{\tau+\sigma \tan \phi}{\sigma-\tau \tan \phi}\right)+\beta, \alpha$ is the best anchoring angle.

\section{The tunnel model of numerical calculation}

1) Model establishment. Using large-scale numerical simulation software FLAC3D, this paper established the three-dimensional numerical model, simulated mine roadway tunneling and supporting construction. The model $\mathrm{x}$ direction is 30m long; y direction is $3 \mathrm{~m}$ long; $\mathrm{z}$ direction is high 30m. The model is divided into 1056 units, 1647 nodes; wherein the $\mathrm{Y}$ forward direction is roadway excavation advance direction.

2) Numerical simulation mechanical parameters (Table 1).In various models, the Monorail Transport roadway width is $\mathrm{L}=3700 \mathrm{~mm}, \mathrm{H}=3500 \mathrm{~mm}$ in high;

Table 1 mechanical parameters of jointed rock mass

\begin{tabular}{|c|c|c|c|c|c|}
\hline Parameter name & bulk modulus & shear stress & internal friction angle & cohesion & tensile strength \\
\hline parameter values & $27 \mathrm{Mpa}$ & $7 \mathrm{Gpa}$ & 350 & $15.3 \mathrm{Kpa}$ & $0.076 \mathrm{Mpa}$ \\
\hline
\end{tabular}

3) Boundary conditions. According to the actual mining experience and mining theory, model boundary applies uniform vertical compressive stress on both sides; model applies horizontal compressive stress; model surface is displacement constraints; left and right are lateral displacement boundary constraint.

\section{Tunnel surrounding rock stress cloud chart analysis}

Figure 1 and Figure 2 respectively for tunnel excavation is supporting and implementation of bolt-grouting rock $X$ direction stress nephogram. As can be seen from the graph, roadway surrounding rock after excavation exists major tensile stress. The peak stress is $6.597 \times 10^{4} \mathrm{pa}$.Top of the tunnel and the surrounding is the area of tensile stress concentration, produce destructive trend more obvious, the bottom pressure tunnel in stress concentration areas. Therefore, the tunnel roof has fall risk, and two sides have danger of wall caving. Adopting bolt-grouting reinforcement, the influence range under tensile stress baseboard and two sides of the roadway are obviously reduced. The roof of the tensile stress concentration area disappeared, and the top is in stable state, thereby illustrating the effect of bolting is remarkable. The peak tensile stress of baseboard and two sides of the roadway is $2.81 \times 10^{4} \mathrm{pa}$.. And compared to the situation of do not support, it reduces about $140 \%$.And the tensile stress in rock mass ultimate stress range; surrounding rock of roadway is in stable; effect of anchor is obvious; surrounding rock of roadway is stably.

Figure 3 and Figure 4 respectively for tunnel excavation is not support and implementation of bolt-grouting reinforcement after rock $\mathrm{Z}$ direction stress nephogram. As can be seen from the graph, $\mathrm{Z}$ direction stress range are basically in the compressive stress after excavation; tensile stress area is very small, not enough to destroy the rock mass. Roadway in excavation without supporting condition, roadway roof and two walls are in the compressive stress concentration area; roadway floor emerged a small area of tensile stress. The peak tensile stress is $4.19 \times 10^{4}$ pa.Adopting 
bolt-shotcrete reinforcement, support changed the stress state of the surrounding rock, making soft rock roadway in rock fracture closure; rock overall situation improved. Through the stress analysis, roadway floor and two shoulder surrounding rock stress range is increased and roadway roof rock stress of roadway floor disappeared; Roadway surrounding rock is in stability overall. The roadway floor in the area of tensile stress concentration is reduced, and its maximum is $4.73 \times 10^{4} \mathrm{p}_{\mathrm{a}}$; the stress can be neglected. From the $\mathrm{Z}$ direction of rock tensile stress nephogram distribution situation, roadway with bolting support, greatly improve the surrounding rock stress state, played a very good supporting effect.

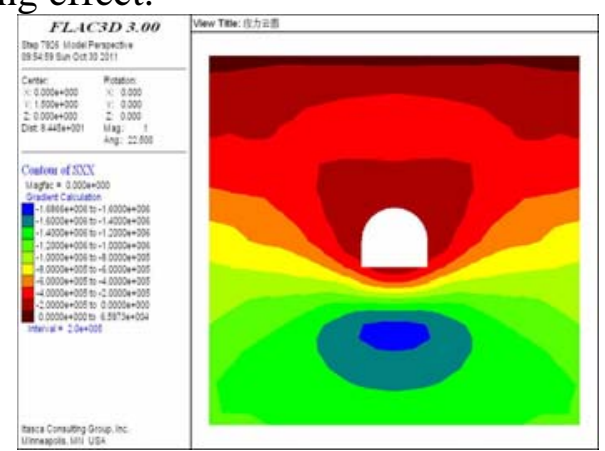

Fig $1 \mathrm{X}$ direction stress nephogram before support roadway

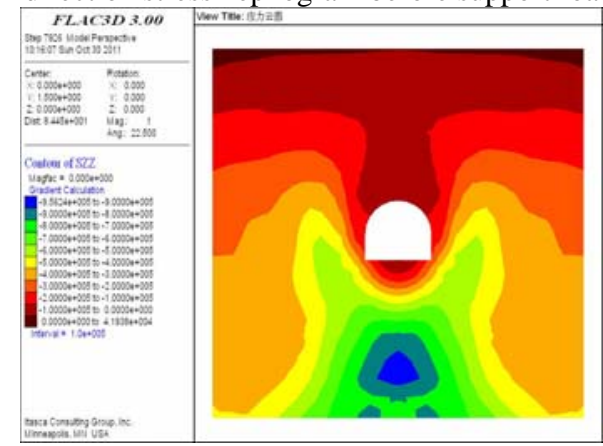

Fig $3 \mathrm{Z}$ direction stress nephogram before support roadway

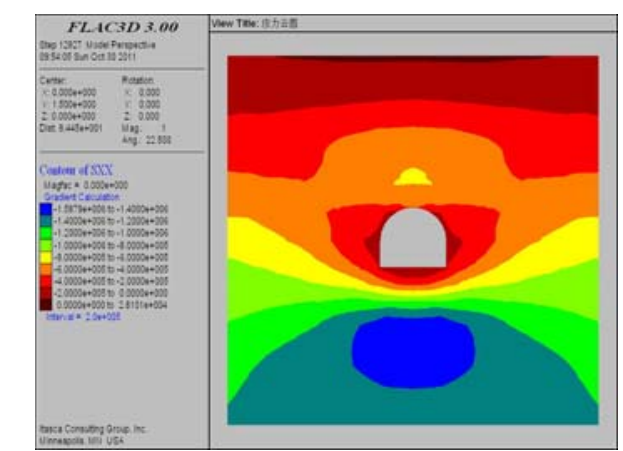

Fig $2 \mathrm{X}$ direction stress nephogram after bolt-grouting

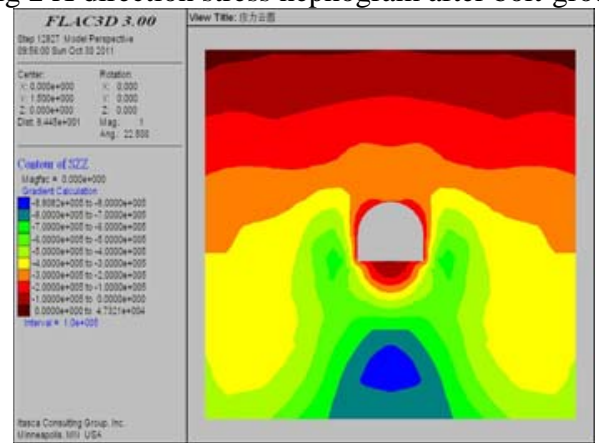

Fig $4 \mathrm{Z}$ direction stress nephogram after bolt-grouting

\section{Roadway surrounding rock displacement analysis}

Fig 5 and Fig 6 respectively are X direction displacement nephogram which are not supporting and bolt-shot Crete in roadway surrounding rock after tunnel excavation. Roadway excavated without supporting; roadway surrounding rock in left moved $1.61 \times 10^{-1} \mathrm{~m}$; roadway surrounding rock in right moved $-1.63 \times 10^{-1} \mathrm{~m}$. Adopting bolt-shot Crete reinforcement of roadway surrounding rock, tunnel surrounding rock displacement around two sides has significantly changed. Roadway surrounding rock in left moved $1.17 \times 10^{-1} \mathrm{~m}$, however roadway surrounding rock in right moved $-1.18 \times 10^{-2} \mathrm{~m}$. By the data, displacement in two sides has reduced $40 \%$ after adopted bolt-shot Crete reinforcement. This shows that the bolt-shot Crete support to prevent wall caving plays a certain effect. Bolt-shotcrete has a obvious effect.
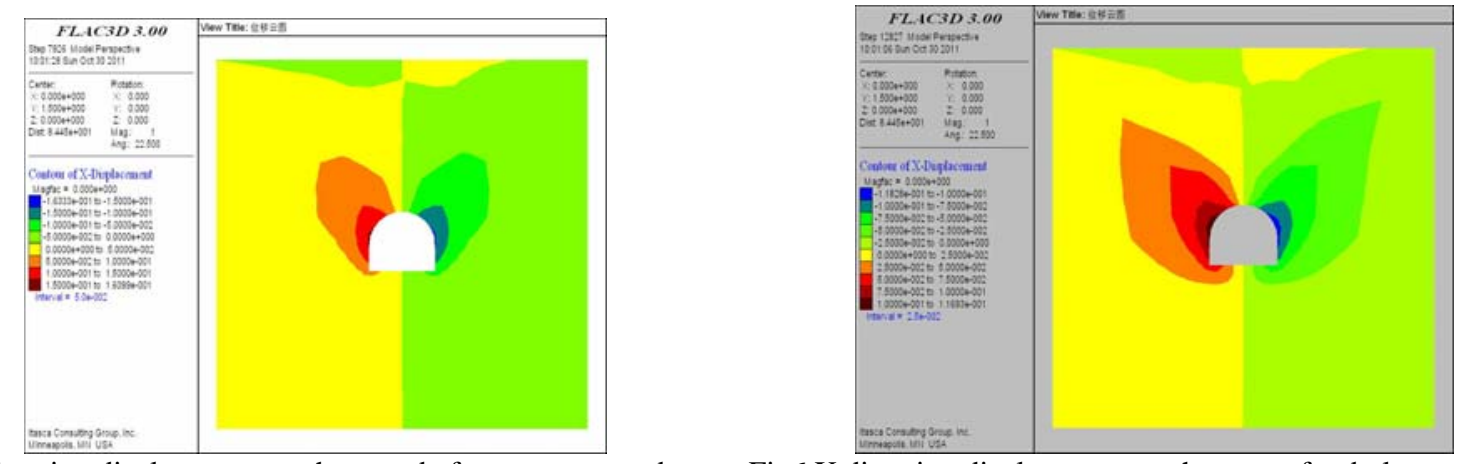

Fig5 X direction displacement nephogram before support roadway Fig6 X direction displacement nephogram after bolt-grouting

Fig 7 and Fig 8 respectively are $\mathrm{Z}$ direction displacement nephogram which are not supporting and bolt-grouting in roadway surrounding rock after tunnel excavation. Roof descended $2.52 \times 10^{-1} \mathrm{~m}$ after 
tunnel excavation; soleplate maximum base expansion is $2.0 \times 10^{-1} \mathrm{~m}$. Adopting bolt-shot Crete reinforcement of roadway surrounding rock, roof squat is $1.22 \times 10^{-1} \mathrm{~m}$ after tunnel excavation; moreover soleplate maximum base expansion is $1.5 \times 10^{-1} \mathrm{~m}$. By the data, displacement in roof and soleplate has reduced $40 \%$. Therefore, after bolt-shot Crete, roadway surrounding rock displacement obviously reduced, so the roadway is in stable, and the measured results are basically the same.
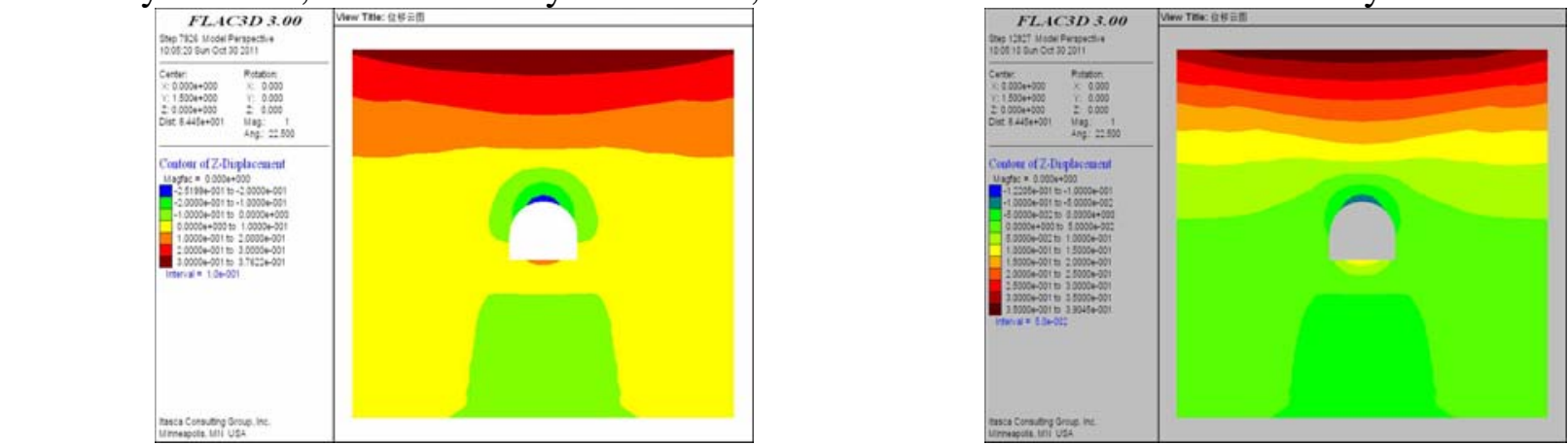

Fig $7 \mathrm{Z}$ direction displacement nephogram before support roadway

Fig 8 Z direction displacement nephogram after bolt-grouting

\section{Conclusion}

Based on the mechanics deduction of anchor rod reinforcement joint constitutive relations v shear strength and optimum anchorage angle, we can obtain the mechanism of action of anchor rod in the jointed rock mass roadway, revealing supporting role of the bolt reinforcement for jointed rock mass reinforcement.

Based on the calculation by Flac3D numerical simulation software, the paper demonstrated: bolt-shot Crete reinforcement to improve the stress condition about joint soft rock roadway surrounding rock、 limit the amount of deformation of roadway has a major role in jointed rock masses for jointed rock masses, bolt-grouting is an effective supporting method. This is technically feasible, and it has great guiding significance in engineering practice.

\section{Acknowledgements}

The authors wish to acknowledge the funding support from Hebei province natural foundation (No: E2012209004); Hebei united University Cultivation Foundation (No: LDPY007); Hebei Provincial Department of education Foundation (No: 2011151).

\section{References}

[1] ZhenXiang Xu. Beijing: China Communications Press, 2002

[2] LiangKui Cheng. Beijing: China Building Industry Press, 2003

[3] YingChun Li. Wuhan geotechnical research institute, 2005

[4] China Science and Technology Information Institute branch. Anchor shotcrete support and testing technology. Beijing: Science and Technology Literature Press,1987.

[5] LiangKui Cheng, JingLun Fan, Jun Han. Beijing: China Building Industry Press, 2003. 